\title{
Pharmacokinetics of Fentanyl Sublingual Spray in Opioid-Naïve Participants: Results of a Phase 1, Multiple Ascending Dose Study
}

\author{
Richard L. Rauck ${ }^{1}$ D. Alexander $\mathrm{Oh}^{2} \cdot$ Neil Singla $^{3}$ - Christian Koch ${ }^{3} \cdot$ Neha Parikh $^{2}$ • \\ Srinivas Nalamachu ${ }^{4} \cdot \mathrm{Jin}_{\mathrm{Yu}^{2}} \cdot$ Steven James $^{2}$
}

Published online: 16 June 2018

(C) The Author(s) 2018

\begin{abstract}
Background and Objectives Fentanyl sublingual spray may be a viable alternative to intravenous (IV) opioids for the treatment of acute pain. As patients with acute pain may include those who have limited prior exposure to opioids, this phase 1, open-label, randomized, multiple ascending-dose study was conducted to assess the pharmacokinetics, pharmacodynamics, safety, and tolerability of multiple doses of fentanyl sublingual spray in opioidnaïve participants. This article primarily reports the pharmacokinetics results.

Methods Study drugs were administered in four dosing cohorts: every $0.5,1,2$, or $4 \mathrm{~h}$ for a maximum of three doses per cohort. Eight fasted individuals per cohort were randomized to either fentanyl sublingual spray $(100,200$, or $400 \mu \mathrm{g})$ or fentanyl citrate IV $50 \mu \mathrm{g}$ (6:2 ratio). Blood samples were collected pre-dose through $24 \mathrm{~h}$ post first dose.

Results A total of 98 healthy adults were enrolled and 96 completed the study. Mean plasma fentanyl concentrations increased with increasing doses of fentanyl sublingual spray administered every $0.5-4 \mathrm{~h}$. With multiple doses,
\end{abstract}

Electronic supplementary material The online version of this article (https://doi.org/10.1007/s40261-018-0658-9) contains supplementary material, which is available to authorized users.

Richard L. Rauck

RRauck@ccrpain.com

1 Carolinas Pain Institute and The Center for Clinical Research, 145 Kimel Park Dr, Ste 330, Winston-Salem, NC 27103, USA

2 Insys Development Company, Inc, Chandler, AZ, USA

3 Lotus Clinical Research, LLC, Pasadena, CA, USA

4 Mid America PolyClinic, Overland Park, KS, USA systemic exposure increased relative to the first dose; shorter dosing intervals resulted in higher concentrations. Analysis of dose proportionality suggested that systemic exposure increased in a linear but slightly greater than dose-proportional manner. Accumulation between the first and last doses of fentanyl sublingual spray was more pronounced with shorter dosing intervals.

Conclusion Dose-dependent fentanyl pharmacokinetics following multiple doses of fentanyl sublingual spray were well characterized in an opioid-naïve population. ClinicalTrials.gov identifier NCT02641340.

\section{Key Points}

In an opioid-naïve population, pharmacokinetics of fentanyl sublingual spray from $100-400 \mu \mathrm{g}$ administered every $0.5-4 \mathrm{~h}$ were characterized with a generally well tolerated safety profile comparable to fentanyl citrate IV $50 \mu \mathrm{g}$.

The fentanyl plasma concentration increased with dose after repeated administration of fentanyl sublingual spray.

\section{Introduction}

Fentanyl is a well-known opioid that was synthesized as a replacement of morphine in 1960 . It is approximately 100 times more potent than morphine [1,2]. Since the approval of fentanyl as an intravenous (IV) injection in 1968 [3], 
other delivery forms of fentanyl have been studied and approved for use in patients with a variety of painful conditions $[4,5]$.

Fentanyl sublingual spray (SUBSYS ${ }^{\circledR}$; Insys Development Company, Inc.; Chandler, AZ, USA) is a potent, short-acting opioid agonist delivered sublingually as a spray that is indicated for the management of breakthrough pain in opioid-tolerant, adult cancer patients. It has demonstrated its efficacy, showing significant pain relief compared to placebo in as early as $5 \mathrm{~min}$ and through $60 \mathrm{~min}$ [4], as well as pharmacokinetic parameters similar to those of IV fentanyl, with a rapid increase in plasma concentrations [6].

Because of its pharmacokinetic profile and rapid onset for pain relief, fentanyl sublingual spray may provide a less invasive, viable alternative to IV opioids for the treatment of acute pain such as postoperative pain, burn dressing change, or initial fracture-related pain in the emergency room. As patients in these settings will likely include those who are opioid naïve or who have limited prior exposure to opioids, it is important to understand the pharmacokinetic characteristics of fentanyl sublingual spray and their impact on safety in an opioid-naïve population. Single-dose pharmacokinetics following fentanyl sublingual spray in healthy opioid-naïve volunteers have been reported previously [7]. This study was conducted to evaluate the pharmacokinetics, pharmacodynamics, safety, and tolerability following multiple doses of fentanyl sublingual spray in an opioid-naïve population. Pharmacodynamics, safety, and tolerability results are reported in a separate publication [8]. Detailed pharmacokinetic results are reported in this article.

\section{Methods}

This was a phase 1, open-label, randomized, multiple ascending-dose study in an opioid-naïve population (ClinicalTrials.gov identifier: NCT02641340). A valid Institutional Review Board (IRB) reviewed and approved the protocol before study initiation. Written informed consent was obtained prior to study participation. Detailed methodology for the treatment period has been previously reported in a separate publication concerning the safety of multiple doses of fentanyl sublingual spray [8].

\subsection{Participants}

Healthy males and non-pregnant, non-breastfeeding females between the ages of 18 and 55 years, with a body mass index $(\mathrm{BMI})<32 \mathrm{~kg} / \mathrm{m}^{2}$, and classified as American Society of Anesthesiologists (ASA) I (a normal healthy person) or ASA II (a patient with mild systemic disease) were eligible for inclusion in the study. Exclusion criteria included hypersensitivity to opioids or naloxone, or severe hypersensitivity reactions (e.g., angioedema) to any drugs; use of opioids or enzyme-altering drugs within 30 days prior to the start of the study; use of any medication that could interfere with respiratory effects within 14 days prior to the first dose of study medication; and positive urine drug screen for drugs of abuse. Participants were also excluded if they had mucositis, cold sores, or periodontal disease of the oral cavity; or piercings of the tongue or anywhere in the oral cavity.

\subsection{Study Design and Treatment}

This was a phase 1, open-label, randomized, multiple ascending-dose study in opioid-naïve participants. This study included a 28-day screening period and a treatment period, with a follow-up phone contact on Day 7. Study drugs were administered in four dosing cohorts: every $0.5,1,2$, or $4 \mathrm{~h}$ for a maximum of three doses per cohort. Eight fasted individuals per cohort were randomized to either fentanyl sublingual spray $(100,200$, or $400 \mu \mathrm{g})$ or fentanyl citrate IV $50 \mu \mathrm{g}$ in a 6:2 ratio. Blood samples were collected pre-dose through $24 \mathrm{~h}$ post first dose. Participants fasted for $10 \mathrm{~h}$ prior to the first dose and through $4 \mathrm{~h}$ post-first dose. To ensure participant safety, participants were closely monitored in an in-clinic setting for up to $24 \mathrm{~h}$ post-first dose.

\subsection{Pharmacokinetic Analysis}

Venous blood samples $(6 \mathrm{ml})$ for the determination of fentanyl plasma concentrations were collected in vacutainer tubes containing $\mathrm{K}_{2}$-EDTA as a preservative, according to the prespecified schedules, dependent on the dosing regimen in each cohort. Human plasma containing fentanyl and the internal standard, fentanyl D5, was extracted with an organic solvent mixture after the addition of sodium carbonate solution (liquid-liquid extraction). Following centrifugation, the organic layer was transferred and evaporated to dryness. An aliquot of the reconstituted extract was injected onto a Sciex API 4000 LC MS equipped with an HPLC column (AB Sciex, Concord, Ontario, Canada). The peak area of the $\mathrm{m} / \mathrm{z} 337 \rightarrow 188$ fentanyl production was measured against the $\mathrm{m} / \mathrm{z}$ $342 \rightarrow 188$ fentanyl D5 internal standard product ion. Quantitation was performed using a weighted linear leastsquares regression. The quantification range was validated from 0.0250 to $5.00 \mathrm{ng} / \mathrm{ml}$ of plasma fentanyl concentration.

The appropriate pharmacokinetic parameters were derived by noncompartmental analysis using Phoenix ${ }^{\circledR}$ WinNonlin (Version 6.3; Pharsight Corporation, Cary, NC, USA), including maximum plasma concentrations after 
first or last dose, determined directly from individual concentration-time data $\left(C_{\max 1}, C_{\max n}\right)$; time of the maximum plasma concentration after first or last dose $\left(T_{\max 1}\right.$ and $T_{\max n}$ ); area under the plasma concentration-time curve from time-zero to the time of the last quantifiable concentration, calculated using the linear-log trapezoidal rule $\left(\mathrm{AUC}_{0-t}\right)$; area under the plasma concentration-time curve from time-zero extrapolated to infinity $\left(\mathrm{AUC}_{0-\mathrm{inf}}\right)$; area under the plasma concentration-time curve during the first and last dosing interval, calculated using the linear-log trapezoidal rule $\left(\mathrm{AUC}_{0-\text { tau1 } 1}\right.$ or $\mathrm{AUC}_{0 \text {-taun }}$, respectively); apparent elimination half-life in the terminal phase by noncompartmental analysis $\left(t_{1 / 2}\right)$; accumulation ratio of $C_{\max }$ $\left(\mathrm{AR}_{C_{\max }}\right)$; accumulation ratio of $\mathrm{AUC}_{\text {tau }}\left(\mathrm{AR}_{\mathrm{AUC}_{\text {tau }}}\right)$; total body clearance of drug (CL); and volume of distribution during terminal phase $\left(V_{\mathrm{Z}}\right)$ for fentanyl following IV administration.

During the pharmacokinetic analysis, plasma drug concentrations that were below the limit of quantitation (BLQ) were treated as zero from time-zero up to the time at which the first quantifiable concentration was observed; embedded and terminal BLQ were treated as "missing." Actual sample times were used in the pharmacokinetic analysis. The $\mathrm{AUC}_{0-\text { inf }}, \mathrm{Vz}, \mathrm{CL}$, and $t_{1 / 2}$ parameters were reported only for concentration-time profiles that exhibited a clear terminal log-linear phase and prespecified criteria outline in the statistical analysis plan.

\subsection{Safety and Pharmacodynamic Analyses}

Safety variables included physical examinations, vital signs, pulse-oximetry, capnography, clinical laboratory testing, electrocardiogram, concomitant medications, and adverse event (AE) assessments. All AEs were coded using Medical Dictionary for Regulatory Activities (MedDRA, version 17.0).

Pharmacodynamic data relevant to respiratory function from capnography, pulse oximetry, and respiration rate measurements were further analyzed. The incidence rates for the primary and additional pharmacodynamic safety endpoints in each of the fentanyl spray groups were compared, within dosing regimen cohort, to the incidence rates in the fentanyl IV group. Detailed safety and pharmacodynamic results are presented in a separate publication [8].

\subsection{Statistical Analysis}

The overall study sample size of 96 participants (eight participants per cohort) was included in the analysis.

Data processing, tabulation of descriptive statistics, and calculation of inferential statistics were performed using SAS $^{\circledR}$ (release 9.2 or higher, SAS Institute Inc.; Cary, NC, USA) for Windows. Unless otherwise indicated, tabulations were by the treatment groups, including the three fentanyl sublingual spray groups and the fentanyl citrate IV group. The fentanyl citrate IV group consisted of all participants treated in the fentanyl citrate IV groups combined over the dosing cohorts. Pharmacokinetic results for the individual treatment groups were summarized using descriptive statistics including arithmetic mean and standard deviation (SD).

The pharmacokinetic parameters $C_{\max n}, \mathrm{AUC}_{0-t}$, and $\mathrm{AUC}_{0-\text { inf }}$ for fentanyl after administration of fentanyl sublingual spray across each sublingual dose level (Cycles 1,2 , and 3) were evaluated for each cohort separately in order to assess dose proportionality. Statistical analyses were performed using a power model with mixed effects of the following general form [9]:

$\ln (\mathrm{PK})=\ln \left(\beta_{0}\right)+\beta_{1} \cdot \ln ($ Dose $)+\varepsilon$,

where

PK is the pharmacokinetic parameter tested (e.g. $C_{\max }$ or AUC)

$\ln \left(\beta_{0}\right)$ is the $y$-intercept,

$\beta_{1}$ is the slope (a value of $\beta 1$ approximately equal to 1 indicates linearity), and

$\varepsilon$ is an error term (Subject was used as the random effects term).

The estimate of $\beta 1$ was reported along with the $\mathrm{p}$-value for the deviation of $\beta 1$ from unity $(\beta 1=1)$.

In addition, natural logarithmic-transformed scatter plots of $C_{\max n}, \mathrm{AUC}_{0-t}$, and $\mathrm{AUC}_{0-\text { inf }}$ for fentanyl after administration of fentanyl sublingual spray by dose were generated (each cohort separately) and the data analyzed using linear regression. The intercept and slope describing the regression line and the goodness of fit $\left(R^{2}\right)$ were also reported within each scatter plot.

\section{Results}

\subsection{Participant Demographics}

A total of 98 opioid-naïve volunteer participants were enrolled in the study, and 96 participants completed treatment.

Overall, the mean (SD) age of study participants was 36.4 (9.87) years and ranged from 20 to 55 years. The majority of participants were male [72 $(75.0 \%)]$, white [55 (57.3\%)], and non-Hispanic/non-Latino [73 (76.0\%)] [8]. There were no remarkable differences in demographic characteristics among participants treated with fentanyl sublingual spray 100,200 , and $400 \mu \mathrm{g}$, or fentanyl citrate IV $50 \mu \mathrm{g}$.

The demographic and baseline characteristics of the safety population for participants treated with fentanyl 
sublingual spray 100,200 , and $400 \mu \mathrm{g}$, and fentanyl citrate IV $50 \mu \mathrm{g}$ across the four dosing frequency cohorts are summarized in Supplemental Tables 1, 2, 3, and 4, respectively.

\subsection{Pharmacokinetics}

The pharmacokinetic analysis population consisted of all randomized participants who received at least one dose of fentanyl and had sufficient plasma data to facilitate the calculation of pharmacokinetic parameters.

Mean plasma fentanyl concentration-time profiles after the administration of multiple doses of fentanyl sublingual spray $(100,200,400 \mu \mathrm{g})$ and fentanyl citrate IV $(50 \mu \mathrm{g})$ are displayed in Fig. 1. Mean plasma fentanyl concentrations increased with an increase in dose of fentanyl sublingual spray between 100 and $400 \mu \mathrm{g}$ (Fig. 1a-c). As expected, higher concentrations were observed for the shorter dosing intervals of $1 \mathrm{~h}$ (Cohort 3 ) and $0.5 \mathrm{~h}$ (Cohort 4) at each dose level. A similar trend was observed after administration of fentanyl citrate IV $50 \mu \mathrm{g}$, with the highest concentrations observed for dosing every $1 \mathrm{~h}$ or $0.5 \mathrm{~h}$, as shown in Fig. $1 \mathrm{~d}$.

Mean fentanyl pharmacokinetic parameters after the administration of multiple doses of fentanyl sublingual spray $(100,200,400 \mu \mathrm{g})$ and fentanyl citrate IV $(50 \mu \mathrm{g})$ are summarized by cohort in Tables $1,2,3$, and 4, respectively.

The mean $C_{\max 1}$ after the first dose of fentanyl sublingual spray $100 \mu \mathrm{g}$ (Cycle 1, Table 1) was similar across cohorts, ranging from $0.159 \mathrm{ng} / \mathrm{ml}$ (Cohort 4) to $0.187 \mathrm{ng} / \mathrm{ml}(\mathrm{Co}-$ hort 2). After the last dose, the mean $\mathrm{C}_{\max n}$ increased relative to the first dose, ranging from $0.225 \mathrm{ng} / \mathrm{ml}$ (Cohort 1) to $0.479 \mathrm{ng} / \mathrm{ml}$ (Cohort 4), and shorter dosing intervals resulted in higher concentrations. Similar trends were observed for $\mathrm{AUC}_{0-\text { tau1 } 1}$ and $\mathrm{AUC}_{0-\text { tau }}$, with an increase in exposure between the first and last doses that was most apparent for the shorter dosing intervals of $1 \mathrm{~h}$ (Cohort 3 ) and $0.5 \mathrm{~h}$ (Cohort 4). Overall systemic exposure to fentanyl after three consecutive doses of fentanyl sublingual spray $100 \mu \mathrm{g}$, based on $\mathrm{AUC}_{0 \text {-inf }}$, varied across cohorts, ranging from $2.172 \mathrm{~h} \cdot \mathrm{ng} / \mathrm{ml}$ (Cohort 1) to $3.427 \mathrm{~h} \cdot \mathrm{ng} / \mathrm{ml}$ (Cohort 3). The mean $\mathrm{t}_{1 / 2}$ after the last dose of fentanyl sublingual spray $100 \mu \mathrm{g}$ was relatively consistent across cohorts, ranging from $4.60 \mathrm{~h}$ (Cohort 1) to $6.06 \mathrm{~h}$ (Cohort 3). The accumulation between the first and last doses of fentanyl sublingual spray $100 \mu \mathrm{g}$ ranged from $1.35\left(\mathrm{AR}_{C_{\max }}\right.$; Cohort 1$)$ to 4.75 $\left(\mathrm{AR}_{\mathrm{AUC}_{\text {tau }}} ;\right.$ Cohort 4$)$, with more pronounced accumulation for shorter dosing intervals (Table 1).

The mean $C_{\max 1}$ after the first dose of fentanyl sublingual spray $200 \mu \mathrm{g}$ (Cycle 2, Table 2) varied across cohorts, ranging from $0.379 \mathrm{ng} / \mathrm{ml}$ (Cohort 4) to $0.522 \mathrm{ng} / \mathrm{ml}$
(Cohort 2), with slightly higher variabilities. After the last dose, the mean $C_{\max n}$ increased relative to the first dose, ranging from $0.548 \mathrm{ng} / \mathrm{ml}$ (Cohort 1) to $1.24 \mathrm{ng} / \mathrm{ml}$ (Cohort 4), and shorter dosing intervals resulted in higher concentrations. Similar trends were observed for $\mathrm{AUC}_{0-\operatorname{tau} 1}$ and $\mathrm{AUC}_{0-\text { tau }}$, with an increase in exposure between the first and last doses that was most apparent for the shorter dosing intervals of $1 \mathrm{~h}$ (Cohort 3) and $0.5 \mathrm{~h}$ (Cohort 4). Overall systemic exposure to fentanyl after three consecutive doses of fentanyl sublingual spray $200 \mu \mathrm{g}$, based on $\mathrm{AUC}_{0-\text { inf }}$, varied across cohorts, ranging from $5.190 \mathrm{~h} \cdot \mathrm{ng} /$ $\mathrm{ml}$ (Cohort 1) to $8.305 \mathrm{~h} \cdot \mathrm{ng} / \mathrm{ml}$ (Cohort 4). The mean $t_{1 / 2}$ after the last dose of fentanyl sublingual spray $200 \mu \mathrm{g}$ was relatively consistent across cohorts, ranging from $5.48 \mathrm{~h}$ (Cohort 4) to $6.68 \mathrm{~h}$ (Cohort 2). The accumulation between the first and last doses of fentanyl sublingual spray $200 \mu \mathrm{g}$ ranged from $1.22\left(\mathrm{AR}_{C_{\max }}\right.$; Cohort 1) to $4.86\left(\mathrm{AR}_{\mathrm{AUC}_{\text {tau }}}\right.$; Cohort 4 ), with more pronounced accumulation for shorter dosing intervals (Table 2).

The mean $C_{\max 1}$ after the first dose of fentanyl sublingual spray $400 \mu \mathrm{g}$ (Cycle 3, Table 3) varied across cohorts, ranging from $0.610 \mathrm{ng} / \mathrm{ml}$ (Cohort 2) to $1.14 \mathrm{ng} / \mathrm{ml}$ (Cohort 1). After the last dose, the mean $C_{\max n}$ increased relative to the first dose, ranging from $1.74 \mathrm{ng} / \mathrm{ml}$ (Cohort 1) to $2.77 \mathrm{ng} / \mathrm{ml}$ (Cohort 3), and shorter dosing intervals resulted in higher concentrations. Similar trends were observed for $\mathrm{AUC}_{0-\operatorname{tau} 1}$ and $\mathrm{AUC}_{0-\operatorname{tau} n}$, with an increase in exposure between the first and last doses that was most apparent for the shorter dosing intervals of $1 \mathrm{~h}$ (Cohort 3 ) and $0.5 \mathrm{~h}$ (Cohort 4). Overall systemic exposure to fentanyl after three consecutive doses of fentanyl sublingual spray $400 \mu \mathrm{g}$, based on $\mathrm{AUC}_{0-\text { inf }}$, varied across cohorts, ranging from $13.43 \mathrm{~h} \cdot \mathrm{ng} / \mathrm{ml}$ (Cohort 2) to $17.93 \mathrm{~h} \cdot \mathrm{ng} / \mathrm{ml}$ (Cohort 1). It should be noted, however, that the variability in $\mathrm{AUC}_{0 \text {-inf }}$ at the $400-\mu \mathrm{g}$ dose level was larger than those at the two lower dose levels. The mean $t_{1 / 2}$ after the last dose of fentanyl sublingual spray $400 \mu \mathrm{g}$ was relatively consistent across cohorts, ranging from $5.31 \mathrm{~h}$ (Cohort 2) to $7.04 \mathrm{~h}$ (Cohort 3). The accumulation between the first and last doses of fentanyl sublingual spray $400 \mu \mathrm{g}$ ranged from $1.64\left(\mathrm{AR}_{C_{\max }}\right.$; Cohort 1) to $4.87\left(\mathrm{AR}_{\mathrm{AUC}_{\text {tau }}}\right.$; Cohort 4), with more pronounced accumulation for shorter dosing intervals (Table 3).

The mean $C_{\max 1}$ after the first dose of fentanyl citrate IV $50 \mu \mathrm{g}$ (Cycles 1, 2, and 3 combined; Table 4) varied similarly across cohorts, ranging from $0.337 \mathrm{ng} / \mathrm{ml}$ (Cohort 1) to $0.549 \mathrm{ng} / \mathrm{ml}$ (Cohort 2). This variability is partly due to the difficulty in capturing peak concentrations after IV administration, as illustrated by the intra-participant variability within each cohort, which ranged from 35.25 to $62.84 \%$. After the last dose, the mean $\mathrm{C}_{\max n}$ increased relative to the first dose, ranging from $0.633 \mathrm{ng} / \mathrm{ml}$ (Cohort 


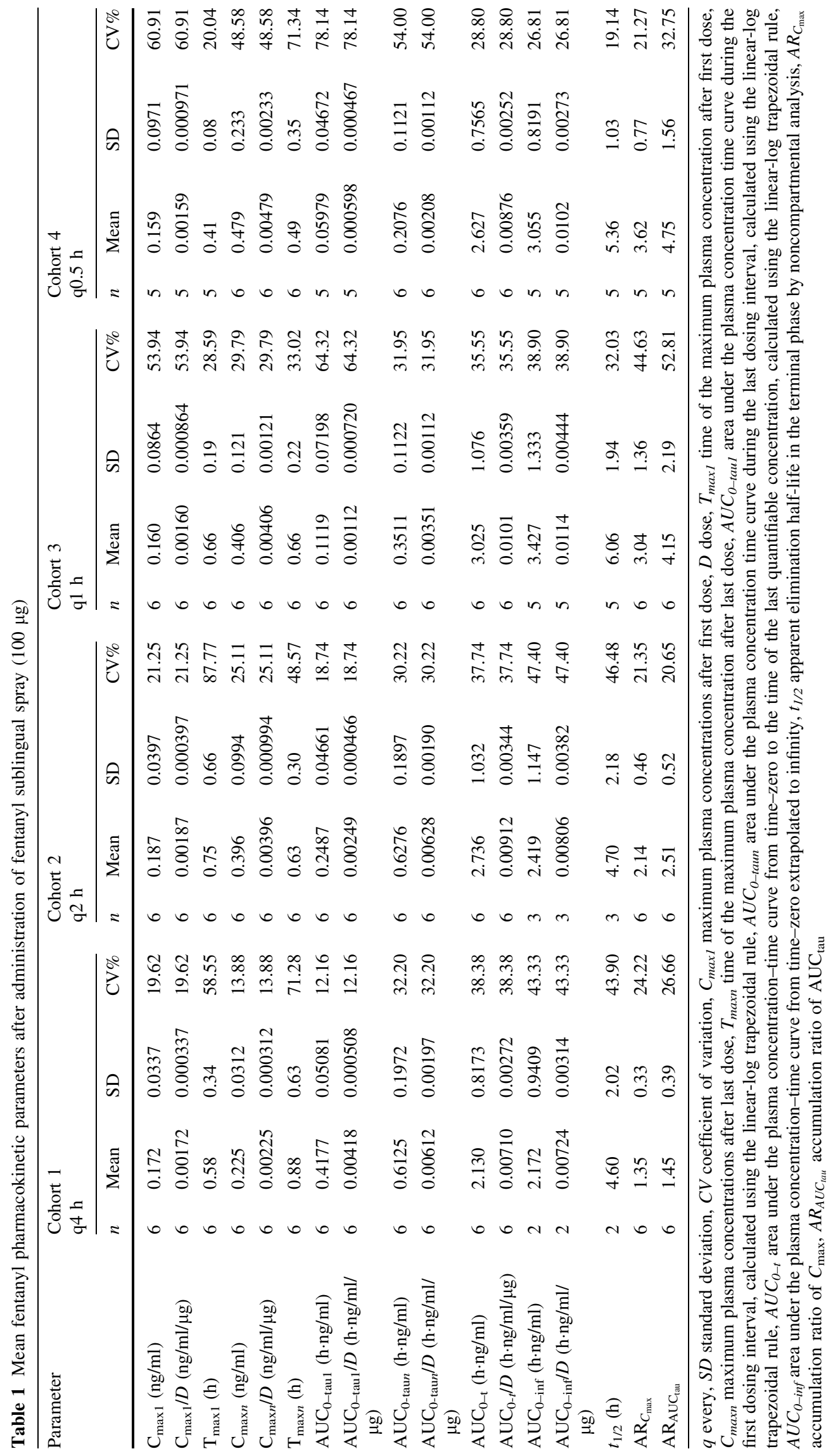




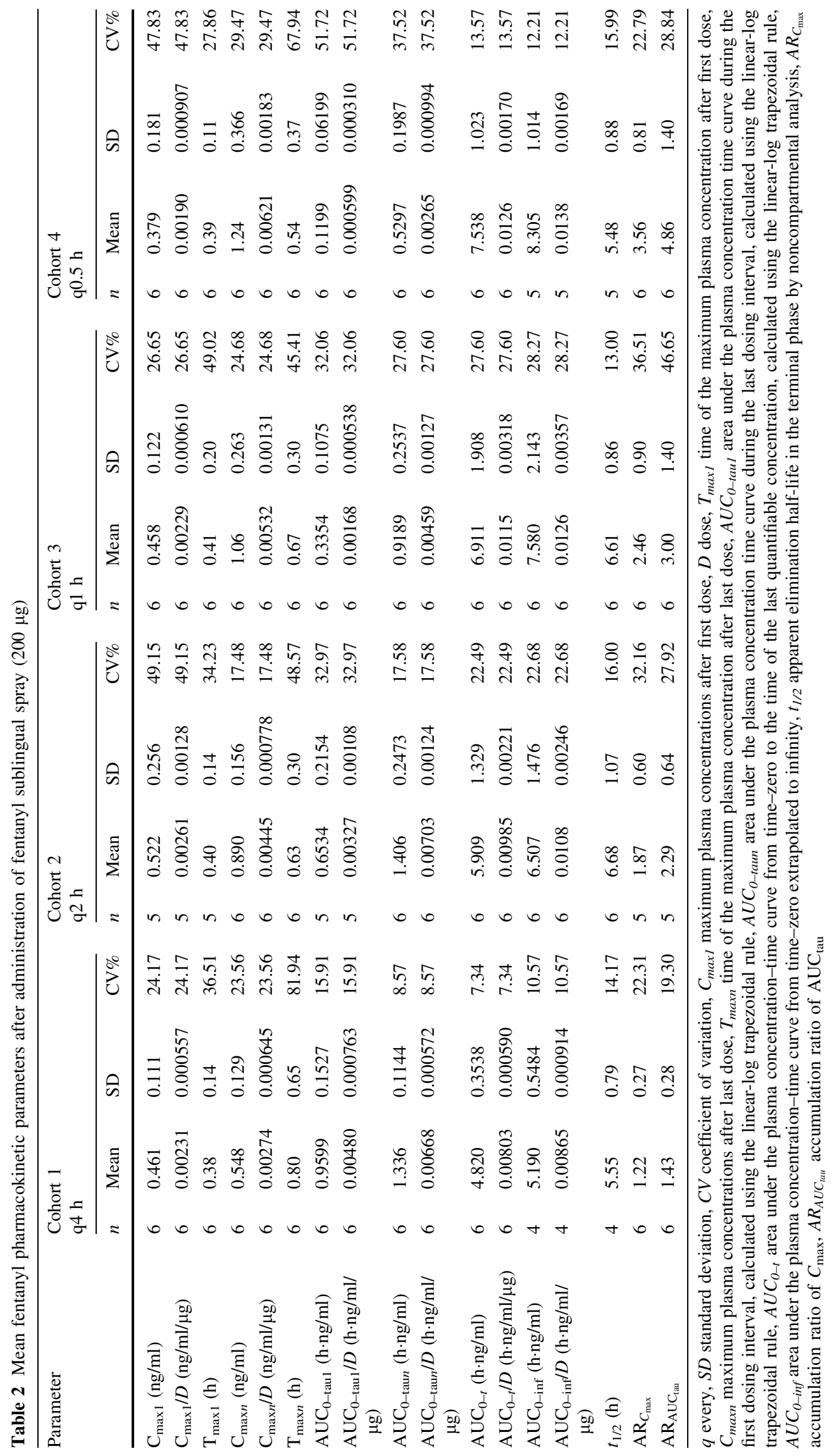


Table 3 Mean fentanyl pharmacokinetic parameters after administration of fentanyl sublingual spray $(400 \mu \mathrm{g})$

\begin{tabular}{|c|c|c|c|c|c|c|c|c|c|c|c|c|}
\hline \multirow[t]{2}{*}{ Parameter } & \multicolumn{3}{|c|}{$\begin{array}{l}\text { Cohort } 1 \\
\text { q4 h }\end{array}$} & \multicolumn{3}{|c|}{$\begin{array}{l}\text { Cohort } 2 \\
\text { q2 h }\end{array}$} & \multicolumn{3}{|c|}{$\begin{array}{l}\text { Cohort } 3 \\
\text { q1 h }\end{array}$} & \multicolumn{3}{|c|}{$\begin{array}{l}\text { Cohort } 4 \\
\text { q0.5 h }\end{array}$} \\
\hline & $n$ & Mean & CV\% & $n$ & Mean & CV\% & $n$ & Mean & CV\% & $n$ & Mean & $\mathrm{CV} \%$ \\
\hline $\mathrm{C}_{\max 1}(\mathrm{ng} / \mathrm{ml})$ & 6 & 1.14 & 35.15 & 6 & 0.610 & 53.68 & 6 & 0.808 & 41.84 & 6 & 0.704 & 68.29 \\
\hline $\mathrm{C}_{\max 1} / D(\mathrm{ng} / \mathrm{ml} / \mu \mathrm{g})$ & 6 & 0.00285 & 35.15 & 6 & 0.00152 & 53.68 & 6 & 0.00202 & 41.84 & 6 & 0.00176 & 68.29 \\
\hline $\mathrm{T}_{\max 1}(\mathrm{~h})$ & 6 & 0.38 & 36.51 & 6 & 0.54 & 67.94 & 6 & 0.65 & 43.24 & 6 & 0.32 & 33.72 \\
\hline $\mathrm{C}_{\max n}(\mathrm{ng} / \mathrm{ml})$ & 5 & 1.74 & 39.48 & 5 & 1.88 & 36.70 & 6 & 2.77 & 32.91 & 6 & 2.41 & 34.19 \\
\hline $\mathrm{C}_{\max n} / D(\mathrm{ng} / \mathrm{ml} / \mu \mathrm{g})$ & 5 & 0.00435 & 39.48 & 5 & 0.00469 & 36.70 & 6 & 0.00693 & 32.91 & 6 & 0.00603 & 34.19 \\
\hline $\mathrm{T}_{\max n}(\mathrm{~h})$ & 5 & 0.51 & 63.13 & 5 & 1.00 & 60.70 & 6 & 0.58 & 51.90 & 6 & 0.71 & 46.91 \\
\hline $\mathrm{AUC}_{0-\mathrm{tau} 1}(\mathrm{~h} \cdot \mathrm{ng} / \mathrm{ml})$ & 6 & 2.535 & 34.16 & 6 & 0.8455 & 53.33 & 6 & 0.6263 & 41.74 & 6 & 0.2277 & 74.31 \\
\hline $\begin{array}{l}\mathrm{AUC}_{0-\mathrm{tau} 1} / D(\mathrm{~h} \cdot \mathrm{ng} / \mathrm{ml} / \\
\mu \mathrm{g})\end{array}$ & 6 & 0.00634 & 34.16 & 6 & 0.00211 & 53.33 & 6 & 0.00157 & 41.74 & 6 & 0.000569 & 74.31 \\
\hline $\mathrm{AUC}_{0-\text { taun }}(\mathrm{h} \cdot \mathrm{ng} / \mathrm{ml})$ & 5 & 4.259 & 54.53 & 5 & 2.872 & 35.94 & 6 & 2.450 & 32.33 & 6 & 0.8782 & 35.65 \\
\hline $\begin{array}{l}\mathrm{AUC}_{0-\mathrm{tau} n} / D(\mathrm{~h} \cdot \mathrm{ng} / \mathrm{ml} / \\
\mu \mathrm{g})\end{array}$ & 5 & 0.0106 & 54.53 & 5 & 0.00718 & 35.94 & 6 & 0.00612 & 32.33 & 6 & 0.00220 & 35.65 \\
\hline $\mathrm{AUC}_{0-t}(\mathrm{~h} \cdot \mathrm{ng} / \mathrm{ml})$ & 5 & 14.77 & 40.80 & 5 & 12.69 & 38.30 & 6 & 15.55 & 28.09 & 6 & 15.34 & 41.71 \\
\hline $\mathrm{AUC}_{0-t} / D(\mathrm{~h} \cdot \mathrm{ng} / \mathrm{ml} / \mu \mathrm{g})$ & 6 & 0.0132 & 37.86 & 6 & 0.00945 & 48.04 & 6 & 0.0130 & 28.09 & 6 & 0.0128 & 41.71 \\
\hline $\mathrm{AUC}_{0-\mathrm{inf}}(\mathrm{h} \cdot \mathrm{ng} / \mathrm{ml})$ & 2 & 17.93 & 68.68 & 4 & 13.43 & 47.37 & 5 & 17.22 & 32.49 & 5 & 14.96 & 44.00 \\
\hline $\begin{array}{l}\mathrm{AUC}_{0-\mathrm{inf}} / D(\mathrm{~h} \cdot \mathrm{ng} / \mathrm{ml} / \\
\mu \mathrm{g})\end{array}$ & 3 & 0.0163 & 46.79 & 5 & 0.00979 & 56.86 & 5 & 0.0144 & 32.49 & 5 & 0.0125 & 44.00 \\
\hline$t_{1 / 2}(\mathrm{~h})$ & 3 & 5.67 & 14.86 & 5 & 5.31 & 45.66 & 5 & 7.04 & 19.52 & 5 & 5.68 & 19.00 \\
\hline $\mathrm{AR}_{C_{\max }}$ & 5 & 1.64 & 28.47 & 5 & 3.11 & 17.79 & 6 & 3.54 & 10.55 & 6 & 4.22 & 54.81 \\
\hline $\mathrm{AR}_{\mathrm{AUC}_{\text {tau }}}$ & 5 & 1.76 & 26.86 & 5 & 3.37 & 13.53 & 6 & 4.08 & 18.93 & 6 & 4.87 & 52.91 \\
\hline
\end{tabular}

$q$ every, $C V$ coefficient of variation, $C_{\max 1}$ maximum plasma concentrations after first dose, $D$ dose, $T_{\max l}$ time of the maximum plasma concentration after first dose, $C_{\operatorname{maxn}}$ maximum plasma concentrations after last dose, $T_{\max n}$ time of the maximum plasma concentration after last dose, $A U C_{0-\text { taul }}$ area under the plasma concentration time curve during the first dosing interval, calculated using the linear-log trapezoidal rule, $A U C_{0-\text { taun }}$ area under the plasma concentration time curve during the last dosing interval, calculated using the linear-log trapezoidal rule, $A U C_{0-t}$ area under the plasma concentration-time curve from time-zero to the time of the last quantifiable concentration, calculated using the linear-log trapezoidal rule, $A U C_{0-i n f}$ area under the plasma concentration-time curve from time-zero extrapolated to infinity, $t_{1 / 2}$ apparent elimina half-life in the terminal phase by noncompartmental analysis, $A R_{C_{\max }}$ accumulation ratio of $C_{\max }, A R_{A U C_{t a u}}$ accumulation ratio of $\mathrm{AUC}$ tau

1) to $0.893 \mathrm{ng} / \mathrm{ml}$ (Cohort 3 ), and there was less variability [based on coefficient of variation (CV)\% within cohort]; although shorter dosing intervals resulted in higher concentrations, this trend for IV administration was not as apparent as that observed for fentanyl sublingual spray. For $\mathrm{AUC}_{0-\text { tau1 }}$ and $\mathrm{AUC}_{0-\text { taun }}$, there was an increase in exposure between the first and last doses that was most apparent for the shortest dosing interval of $0.5 \mathrm{~h}$ (Cohort 4). Overall systemic exposure to fentanyl after three consecutive doses of fentanyl citrate IV $50 \mu \mathrm{g}$, based on $\mathrm{AUC}_{0-\mathrm{inf}}$, was consistent across cohorts and ranged from $2.358 \mathrm{~h} \cdot \mathrm{ng} / \mathrm{ml}$ (Cohort 3) to $2.882 \mathrm{~h} \cdot \mathrm{ng} / \mathrm{ml}$ (Cohort 1 ). The mean $t_{1 / 2}$ after the last dose of fentanyl citrate IV $50 \mu \mathrm{g}$ was similar across cohorts, ranging from $4.69 \mathrm{~h}$ (Cohort 3) to $6.90 \mathrm{~h}$ (Cohort 1). The accumulation between the first and last doses of fentanyl citrate IV $50 \mu \mathrm{g}$ ranged from $1.57\left(\mathrm{AR}_{C_{\max }}\right.$, Cohort 2) to $3.08\left(\mathrm{AR}_{C_{\max }}\right.$, Cohort 1) (Table 4).

In general, pharmacokinetics after three consecutive doses of fentanyl sublingual spray behaved similarly to that after fentanyl citrate IV $50 \mu \mathrm{g}$, as follows: (1) after the last dose, the peak and extent of fentanyl exposures increased relative to the first dose and shorter dosing intervals resulted in higher exposures; (2) the mean $t_{1 / 2}$ after the last dose of fentanyl was similar across cohorts; (3) the accumulation between the first and last doses of fentanyl was observed for all dosing intervals, with more pronounced accumulation for shorter dosing intervals.

The statistical analysis of dose proportionality of fentanyl sublingual spray $(100-400 \mu \mathrm{g})$ is summarized in Table 5. The results of the dose proportionality assessments by the power model showed that dose proportionality could not be statistically established over the full dose range of 100-400 $\mu \mathrm{g}$ fentanyl sublingual spray. The slope $(\beta 1)$ estimates for pharmacokinetic exposure parameters were within 0.80 and 1.25 for Cohorts 2 and 4 , but greater than 1 (ranging from 1.1764 to 1.4615 ) for Cohorts 1 and 3, with variable $90 \%$ confidence intervals. The dose proportionality results are shown with a linear slope and correlation coefficient by cohort for fentanyl $C_{\max n}$ in Fig. 2a, fentanyl $\mathrm{AUC}_{0-\text { inf }}$ in Fig. 2b, and fentanyl $\mathrm{AUC}_{0-t}$ in Fig. 2c, showing linear dose-dependent increases of the pharmacokinetic parameters tested. In summary, systemic 
Table 4 Mean fentanyl pharmacokinetic parameters after administration of fentanyl citrate IV (50 $\mu \mathrm{g})$

\begin{tabular}{|c|c|c|c|c|c|c|c|c|c|c|c|c|}
\hline \multirow[t]{2}{*}{ Parameter } & \multicolumn{3}{|c|}{$\begin{array}{l}\text { Cohort } 1 \\
\mathrm{q} 4 \mathrm{~h}\end{array}$} & \multicolumn{3}{|c|}{$\begin{array}{l}\text { Cohort } 2 \\
\text { q2 h }\end{array}$} & \multicolumn{3}{|c|}{$\begin{array}{l}\text { Cohort } 3 \\
\text { q1 h }\end{array}$} & \multicolumn{3}{|c|}{$\begin{array}{l}\text { Cohort } 4 \\
\text { q0.5 h }\end{array}$} \\
\hline & $n$ & Mean & $\mathrm{CV} \%$ & $n$ & Mean & $\mathrm{CV} \%$ & $n$ & Mean & $\mathrm{CV} \%$ & $n$ & Mean & $\mathrm{CV} \%$ \\
\hline $\mathrm{C}_{\max 1}(\mathrm{ng} / \mathrm{ml})$ & 6 & 0.337 & 62.84 & 6 & 0.549 & 40.59 & 6 & 0.477 & 35.25 & 6 & 0.369 & 54.09 \\
\hline $\mathrm{C}_{\max 1} / D(\mathrm{ng} / \mathrm{ml} / \mu \mathrm{g})$ & 6 & 0.00673 & 62.84 & 6 & 0.0110 & 40.59 & 6 & 0.00955 & 35.25 & 6 & 0.00738 & 54.09 \\
\hline $\mathrm{T}_{\max 1}(\mathrm{~h})$ & 6 & 0.16 & 101.80 & 6 & 0.08 & 0.00 & 6 & 0.08 & 0.00 & 6 & 0.13 & 50.02 \\
\hline $\mathrm{C}_{\max n}(\mathrm{ng} / \mathrm{ml})$ & 6 & 0.633 & 14.36 & 6 & 0.731 & 26.84 & 5 & 0.893 & 26.94 & 6 & 0.815 & 18.78 \\
\hline $\mathrm{C}_{\max n} / D(\mathrm{ng} / \mathrm{ml} / \mu \mathrm{g})$ & 6 & 0.0127 & 14.36 & 6 & 0.0146 & 26.84 & 5 & 0.0179 & 26.94 & 6 & 0.0163 & 18.78 \\
\hline $\mathrm{T}_{\max n}(\mathrm{~h})$ & 6 & 0.08 & 0.00 & 6 & 0.09 & 7.92 & 5 & 0.09 & 8.62 & 6 & 0.09 & 18.26 \\
\hline $\operatorname{AUC}_{0-\operatorname{tau} 1}(\mathrm{~h} \cdot \mathrm{ng} / \mathrm{ml})$ & 6 & 0.3298 & 25.40 & 6 & 0.3020 & 11.27 & 6 & 0.2182 & 25.41 & 6 & 0.1093 & 34.27 \\
\hline $\begin{array}{l}\mathrm{AUC}_{0-\mathrm{tau} 1} / D(\mathrm{~h} \cdot \mathrm{ng} / \mathrm{ml} / \\
\mu \mathrm{g})\end{array}$ & 6 & 0.00660 & 25.40 & 6 & 0.00604 & 11.27 & 6 & 0.00436 & 25.41 & 6 & 0.00219 & 34.27 \\
\hline $\mathrm{AUC}_{0-\operatorname{tau} n}(\mathrm{~h} \cdot \mathrm{ng} / \mathrm{ml})$ & 6 & 0.6133 & 21.55 & 6 & 0.6106 & 18.59 & 5 & 0.3964 & 21.95 & 6 & 0.2578 & 10.19 \\
\hline $\begin{array}{l}\mathrm{AUC}_{0-\mathrm{tau} n} / D(\mathrm{~h} \cdot \mathrm{ng} / \mathrm{ml} / \\
\mu \mathrm{g})\end{array}$ & 6 & 0.0123 & 21.55 & 6 & 0.0122 & 18.59 & 5 & 0.00793 & 21.95 & 6 & 0.00516 & 10.19 \\
\hline $\mathrm{AUC}_{0-t}(\mathrm{~h} \cdot \mathrm{ng} / \mathrm{ml})$ & 6 & 2.139 & 26.38 & 6 & 2.400 & 24.23 & 5 & 2.211 & 34.50 & 6 & 2.286 & 17.34 \\
\hline $\mathrm{AUC}_{0-t} / D(\mathrm{~h} \cdot \mathrm{ng} / \mathrm{ml} / \mu \mathrm{g})$ & 6 & 0.0143 & 26.38 & 6 & 0.0160 & 24.23 & 6 & 0.0146 & 31.32 & 6 & 0.0152 & 17.34 \\
\hline $\mathrm{AUC}_{0-\mathrm{inf}}(\mathrm{h} \cdot \mathrm{ng} / \mathrm{ml})$ & 1 & 2.882 & 0.00 & 5 & 2.628 & 28.25 & 4 & 2.358 & 40.07 & 6 & 2.517 & 17.65 \\
\hline $\begin{array}{l}\mathrm{AUC}_{0-\text { inf }} / D(\mathrm{~h} \cdot \mathrm{ng} / \mathrm{ml} / \\
\mu \mathrm{g})\end{array}$ & 1 & 0.0192 & 0.00 & 5 & 0.0175 & 28.25 & 4 & 0.0157 & 40.07 & 6 & 0.0168 & 17.65 \\
\hline$t_{1 / 2}(\mathrm{~h})$ & 1 & 6.90 & 0.00 & 5 & 5.13 & 43.75 & 4 & 4.69 & 34.84 & 6 & 5.42 & 17.33 \\
\hline CL (L/h) & 1 & 52.05 & 0.00 & 5 & 61.48 & 32.25 & 4 & 72.29 & 40.05 & 6 & 61.22 & 18.02 \\
\hline $\mathrm{Vz}(\mathrm{L})$ & 1 & 518.2 & 0.00 & 5 & 413.3 & 28.35 & 4 & 439.7 & 10.99 & 6 & 468.4 & 11.08 \\
\hline $\mathrm{AR}_{C_{\max }}$ & 6 & 3.08 & 79.40 & 6 & 1.57 & 49.04 & 5 & 2.19 & 57.13 & 6 & 2.72 & 50.85 \\
\hline $\mathrm{AR}_{\mathrm{AUC}_{\text {tau }}}$ & 6 & 1.90 & 18.15 & 6 & 2.04 & 18.10 & 5 & 1.89 & 17.72 & 6 & 2.57 & 33.14 \\
\hline
\end{tabular}

$I V$ intravenous, $q$ every, $C V$ coefficient of variation, $C_{\max l}$ maximum plasma concentrations after first dose, $D$ dose, $T_{\max l}$ time of the maximum plasma concentration after first dose, $C_{\max }$ maximum plasma concentrations after last dose, $T_{\operatorname{maxn}}$ time of the maximum plasma concentration after last dose, $A U C_{0-\text { taul }}$ area under the plasma concentration time curve during the first dosing interval, calculated using the linear-log trapezoidal rule, $A U C_{0-\text { taun }}$ area under the plasma concentration time curve during the last dosing interval, calculated using the linear-log trapezoidal rule, $A U C_{0-t}$ area under the plasma concentration-time curve from time-zero to the time of the last quantifiable concentration, calculated using the linear-log trapezoidal rule, $A U C_{0-i n f}$ area under the plasma concentration-time curve from time-zero extrapolated to infinity, $t_{1 / 2}$ apparent elimination half-life in the terminal phase by noncompartmental analysis, $A R_{C_{\max }}$ accumulation ratio of $C_{\max }, A R_{A U C_{\text {tau }}}$ accumulation ratio of $\mathrm{AUC}_{\mathrm{tau}}$

exposure following multiple doses of fentanyl sublingual spray appeared to increase in a slightly greater than doseproportional manner over the range of $100-400 \mu \mathrm{g}$.

\subsection{Safety and Pharmacodynamics Analyses}

There were no deaths or serious AEs reported during the conduct of this clinical trial. Safety results and pharmacodynamic analysis relevant to respiratory function are presented in a separate publication [8].

\section{Discussion}

Fentanyl sublingual spray was designed to provide rapid onset of analgesia and has demonstrated pharmacokinetic parameters similar to those of IV fentanyl, showing a rapid increase in plasma concentrations after quantifiable mean plasma concentrations of fentanyl observed at the first blood collection timepoint (5 min) after administration $[6,10]$. Because of these advantages, it has been postulated that fentanyl sublingual spray might be appropriately used for acute needs (e.g., procedurally or in emergency departments) or for post-operative pain. However, patients likely to receive opioids in these settings will include those who are opioid naïve or who have limited prior exposure to opioids. Consequently, it is important to understand the relationship between systemic exposure of fentanyl following administration of fentanyl sublingual spray and its effects on respiratory function in an opioid-naïve or nontolerant population. Therefore, a phase 1 , single ascendingdose study was conducted in an opioid-naïve population to evaluate the pharmacokinetics, pharmacodynamics, safety, and tolerability of fentanyl sublingual spray prior to entering clinical trials within acute pain and related settings [7]. Overall, a single-dose administration of fentanyl 
A

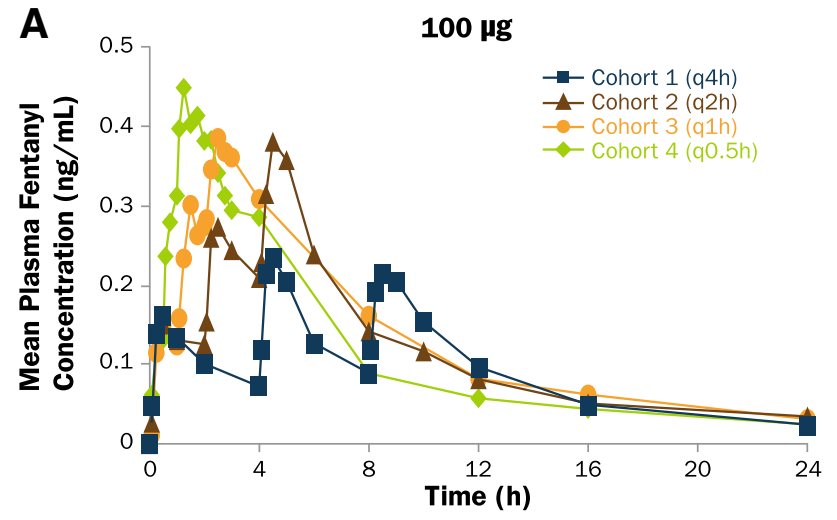

C

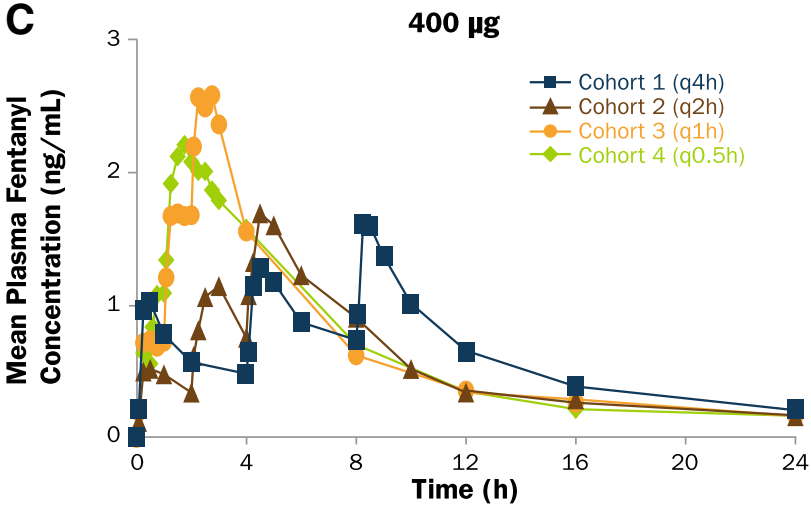

Fig. 1 Mean fentanyl concentration-time profiles after administration of a fentanyl sublingual spray $100 \mu \mathrm{g}$, b fentanyl sublingual spray $200 \mu \mathrm{g}$, c fentanyl sublingual spray $400 \mu \mathrm{g}$, or d fentanyl citrate IV
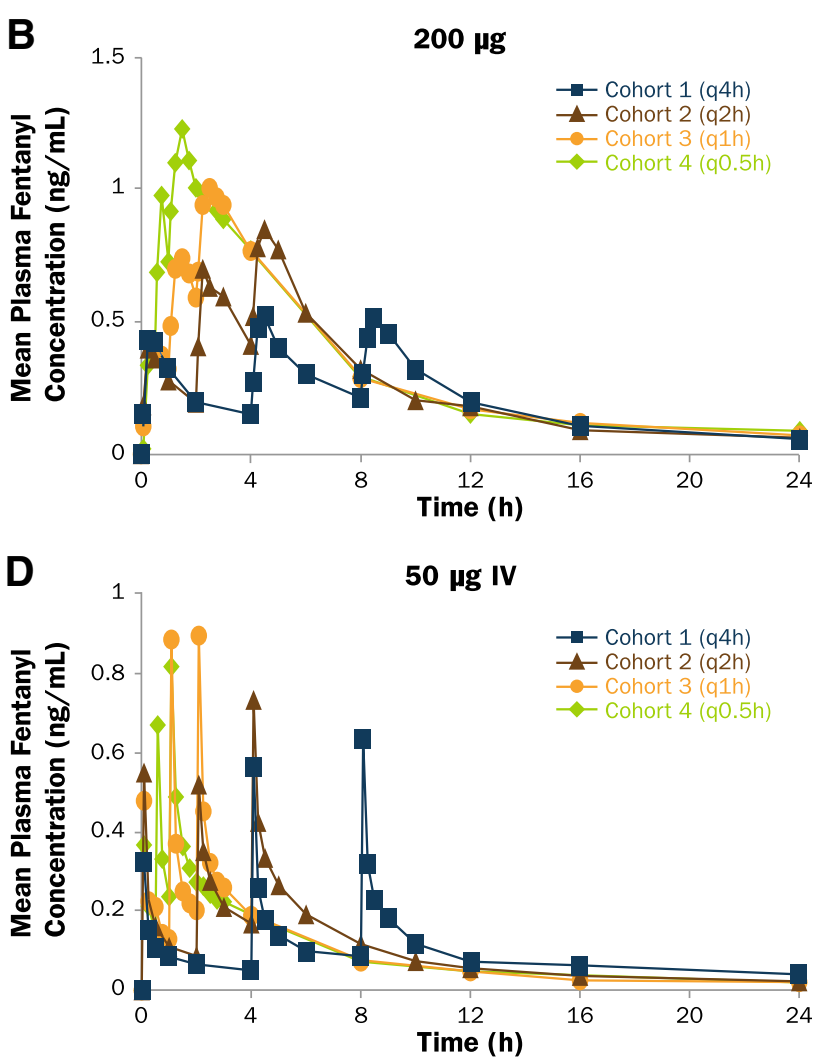

$50 \mu$ g. Cohort 1 , every 4 h; Cohort 2, every 2 h; Cohort 3, every 1 h; Cohort 4 , every $0.5 \mathrm{~h}$

Table 5 Assessment of dose proportionality of fentanyl sublingual spray (100-400 $\mu \mathrm{g})$

\begin{tabular}{|c|c|c|c|c|c|c|}
\hline Cohort & Dependent variable & Model variable & Estimate $(\beta 1)$ & Lower $\mathrm{CL}^{\mathrm{a}}$ & Upper $C^{a}$ & $p$ value $^{\mathrm{b}}$ \\
\hline \multirow[t]{3}{*}{ Cohort 1 (q4 h) } & $\ln \left(\mathrm{C}_{\max n}\right)$ & $\ln ($ Dose $)$ & 1.4336 & 1.2382 & 1.6290 & $<0.0001$ \\
\hline & $\ln \left(\mathrm{AUC}_{0-t}\right)$ & $\ln ($ Dose $)$ & 1.3945 & 1.1581 & 1.6309 & $<0.0001$ \\
\hline & $\ln \left(\mathrm{AUC}_{0-\mathrm{inf}}\right)$ & $\ln ($ Dose $)$ & 1.4615 & 0.9447 & 1.9783 & 0.0015 \\
\hline \multirow[t]{3}{*}{ Cohort 2 (q2 h) } & $\ln \left(\mathrm{C}_{\max n}\right)$ & $\ln ($ Dose $)$ & 1.0993 & 0.8803 & 1.3183 & $<0.0001$ \\
\hline & $\ln \left(\mathrm{AUC}_{0-t}\right)$ & $\ln ($ Dose $)$ & 1.0989 & 0.8057 & 1.3921 & $<0.0001$ \\
\hline & $\ln \left(\mathrm{AUC}_{0-\text { inf }}\right)$ & $\ln ($ Dose $)$ & 1.1925 & 0.7927 & 1.5924 & 0.0002 \\
\hline \multirow[t]{3}{*}{ Cohort 3 (q1 h) } & $\ln \left(\mathrm{C}_{\max n}\right)$ & $\ln ($ Dose $)$ & 1.3800 & 1.1637 & 1.5962 & $<0.0001$ \\
\hline & $\ln \left(\mathrm{AUC}_{0-t}\right)$ & $\ln ($ Dose $)$ & 1.1932 & $\mathrm{NE}$ & $\mathrm{NE}$ & $\mathrm{NE}$ \\
\hline & $\ln \left(\mathrm{AUC}_{0-\mathrm{inf}}\right)$ & $\ln ($ Dose $)$ & 1.1764 & 0.9237 & 1.4291 & $<0.0001$ \\
\hline \multirow[t]{3}{*}{ Cohort 4 (q0.5 h) } & $\ln \left(\mathrm{C}_{\max n}\right)$ & $\ln ($ Dose $)$ & 1.2031 & 0.9227 & 1.4836 & $<0.0001$ \\
\hline & $\ln \left(\mathrm{AUC}_{0-t}\right)$ & $\ln ($ Dose $)$ & 1.2463 & 1.0037 & 1.4888 & $<0.0001$ \\
\hline & $\ln \left(\mathrm{AUC}_{0-\mathrm{inf}}\right)$ & $\ln ($ Dose $)$ & 1.1190 & 0.8516 & 1.3864 & $<0.0001$ \\
\hline
\end{tabular}

$q$ every, $C_{\operatorname{maxn}}$ maximum plasma concentrations after last dose, $A U C_{0-t}$ area under the plasma concentration-time curve from time-zero to the time of the last quantifiable concentration, calculated using the linear-log trapezoidal rule, $A U C_{0-i n f}$ area under the plasma concentration-time curve from time-zero to infinity, $N E$ not estimable

${ }^{\mathrm{a}} 90 \%$ confidence intervals (lower and upper)

${ }^{\mathrm{b}}$ Significant difference from unity (1.0000), defined a priori as $p<0.05$

sublingual spray at doses ranging from 100 to $800 \mu \mathrm{g}$ was generally well tolerated. Results suggested that doses up to $200 \mu \mathrm{g}$ may be safely administered to a healthy opioid- naïve population with routine monitoring and that doses of 400-800 $\mu \mathrm{g}$ may be administered in a monitored setting where nasal cannula oxygenation is available [7]. 

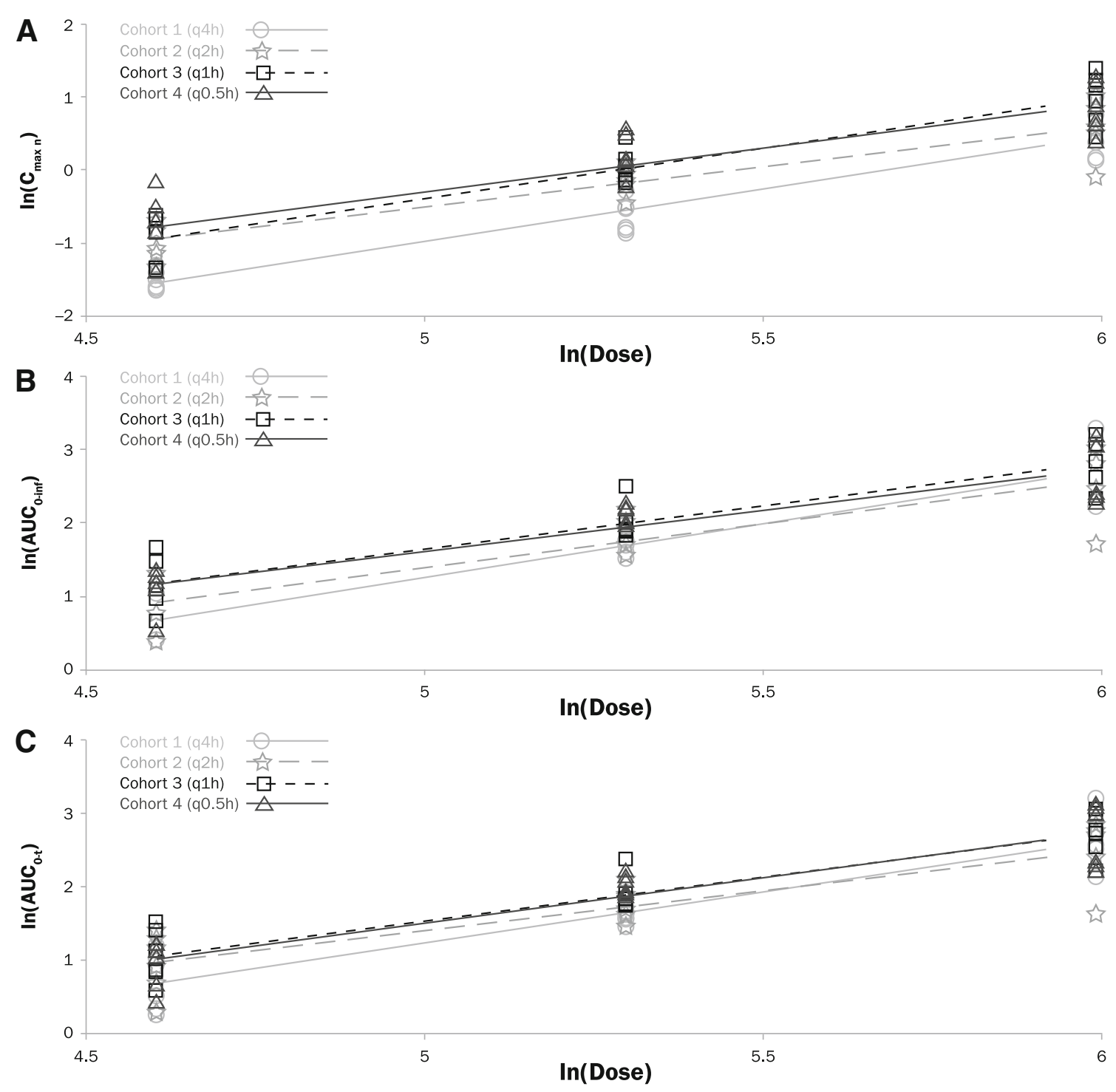

Fig. 2 Dose proportionality of fentanyl a $C_{\max n}$, b $\mathrm{AUC}_{0-\text { inf }}$, and c $\mathrm{AUC}_{0-t}$ after administration of fentanyl sublingual spray $100 \mu \mathrm{g}$ (Cycle 1), $200 \mu \mathrm{g}$ (Cycle 2), and $400 \mu \mathrm{g}$ (Cycle 3) every $4 \mathrm{~h}$ (Cohort $1), 2 \mathrm{~h}$ (Cohort 2), $1 \mathrm{~h}$ (Cohort 3 ), or $0.5 \mathrm{~h}$ (Cohort 4$). A U C_{0-t}$ area under the plasma concentration-time curve from time-zero to the

Furthermore, mean plasma concentrations and mean exposure parameters of fentanyl following fentanyl sublingual spray were comparable to results in previous studies [6, 10] over the dose range from 100 to $800 \mu \mathrm{g}$ [7].

In the present study, the pharmacokinetics, pharmacodynamics, safety, and tolerability of multiple doses of fentanyl sublingual spray were further investigated in opioid-naïve participants at one clinical site, and compared with those of multiple doses of IV fentanyl citrate.

In general, multiple-dose pharmacokinetics of fentanyl were consistent with previously reported single-dose pharmacokinetic profiles following fentanyl sublingual spray or fentanyl citrate IV. Mean plasma fentanyl time of the last quantifiable concentration, calculated using the linear$\log$ trapezoidal rule, $A U C_{O-i n f}$ area under the plasma concentrationtime curve from time-zero extrapolated to infinity, calculated using the linear-log trapezoidal rule, $C_{\operatorname{maxn}}$ maximum plasma concentrations after last dose

concentrations increased with an increase in dose of fentanyl sublingual spray between $100 \mu \mathrm{g}$ (Cycle 1) and $400 \mu \mathrm{g}$ (Cycle 3). As expected, higher concentrations were observed for the shortest dosing intervals of $1 \mathrm{~h}$ (Cohort 3) and $0.5 \mathrm{~h}$ (Cohort 4). A similar trend was observed after administration of fentanyl citrate IV $50 \mu \mathrm{g}$, with the highest concentrations observed for more frequent dosing, every $1 \mathrm{~h}$ (Cohort 3 ) or $0.5 \mathrm{~h}$ (Cohort 4 ). The $t_{1 / 2}$ was approximately $5-7 \mathrm{~h}$ for both fentanyl sublingual spray and fentanyl citrate IV administration. During multiple doses of fentanyl sublingual spray, $C_{\max n}$ increased relative to the first dose, and shorter dosing intervals resulted in higher concentrations. Similar trends were observed for 
$\mathrm{AUC}_{0-\mathrm{tau}}$, with an increase in exposure between the first and last doses, which was most apparent for the shorter dosing intervals of $1 \mathrm{~h}$ (Cohort 3 ) and $0.5 \mathrm{~h}$ (Cohort 4). The accumulation ratios between the first and last doses of fentanyl sublingual spray ranged from approximately 1.2 to 1.8 (every $4 \mathrm{~h}$ ), 1.9 to 3.4 (every $2 \mathrm{~h}$ ), 2.5 to 4.2 (every $1 \mathrm{~h}$ ), to 3.6 to 4.9 (every $0.5 \mathrm{~h}$ ), with more pronounced accumulation for shorter dosing intervals. Similarly, accumulation ratios between the first and last doses of fentanyl citrate IV ranged from approximately 1.9 to 3.1 (every $4 \mathrm{~h}$ ), 1.6 to 2.0 (every $2 \mathrm{~h}$ ) and 1.9 to 2.2 (every $1 \mathrm{~h}$ ) to 2.6 to 2.7 (every $0.5 \mathrm{~h}$ ), with comparable accumulation across all dosing intervals but slightly less than with sublingual sprays.

Analysis of dose proportionality using the power model [9] suggested that maximum fentanyl exposure $\left(C_{\max n}\right)$ and total fentanyl exposure $\left(\mathrm{AUC}_{0-t}\right.$ and $\left.\mathrm{AUC}_{0-\text { inf }}\right)$ increased in a linear manner, with an increase in dose following multiple-dose administrations of fentanyl sublingual spray at all dosing intervals ranging from 0.5 to $4 \mathrm{~h}$. From the linear regression through log-transformed parameter values versus log-dose using all dose levels within each dosing interval, the slope of the regression line ranged from 1.099 $\left(\mathrm{AUC}_{0-t}\right.$, every $\left.2 \mathrm{~h}\right)$ to $1.462\left(\mathrm{AUC}_{0-\text { inf }}\right.$, every $\left.4 \mathrm{~h}\right)$, suggesting that the increase in exposure was slightly greater than dose proportional. This may be due to some accumulation at the higher dose following short dosing frequency, small number of subjects, and inter-subject variability.

There were no appreciable differences in safety-related pharmacodynamic changes following fentanyl sublingual spray administration for capnography, pulse oximetry, hypoxia, nausea, and vomiting compared with fentanyl citrate IV $50 \mu \mathrm{g}$ [8].

\section{Conclusions}

Dose-dependent fentanyl pharmacokinetics following multiple doses of fentanyl sublingual spray were well characterized in healthy opioid-naïve adults. During multiple doses of fentanyl sublingual spray, $C_{\max n}$ increased relative to the first dose, and shorter dosing intervals resulted in higher concentrations. Similar trends were observed for $\mathrm{AUC}_{0-\mathrm{tau} n}$, with an increase in exposure between the first and last doses, which was most apparent at shorter dosing intervals. The accumulation ratios between the first and last doses of fentanyl sublingual spray ranged from approximately 1.2 to 4.9 , with more pronounced accumulation for shorter dosing intervals. Systemic exposure following multiple doses of fentanyl sublingual spray appeared to increase in a slightly greater than dose-proportional manner over the range of $100-400 \mu \mathrm{g}$. Three repeated doses of fentanyl sublingual spray administered at doses of 100, 200, and $400 \mu \mathrm{g}$ and at dosing intervals ranging from every 0.5 to $4 \mathrm{~h}$ were generally well tolerated in a healthy opioidnaïve population.

Acknowledgements Editorial support was provided under the direction of the authors by Synchrony Medical Communications, LLC, West Chester, PA.

\section{Compliance with ethical standards}

Funding Funding for this study and editorial support was provided by Insys Development Company, Inc., Chandler, AZ.

Conflict of interest RR reports serving as a consultant or advisory board member or receiving research funding from the Alfred Mann Foundation, Archimedes, BioDelivery Sciences International, Inc., Insys Development Company, Inc., Jazz Pharmaceuticals, Meda, Medasys, Inc., and Medtronic, Inc.; serving on the speakers' bureau for Jazz Pharmaceuticals; and receiving research funding from Alfred Mann Foundation, Bioness, Boston Scientific, Collegium Pharmaceuticals, CNS Therapeutics, Jazz Pharmaceuticals, Medtronic, Inc., Myoscience, NeurAxon, Inc., Spinal Modulation, Spinal Restoration, and St. Jude Medical. DAO, NP, JY, and SJ are employees of and hold stock in Insys Development Company, Inc. CK is an employee of Lotus Clinical Research, LLC, which received grants for conducting clinical investigations in connection with this trial. NS is owner and founder of Lotus Clinical Research, LLC, which received grants for conducting clinical investigations in connection with this trial; reports receiving research funding from Acacia Pharma Ltd, AcelRx Pharmaceuticals, Inc., Alkermes, Inc., AMAG Pharmaceuticals, Inc., Aponia Laboratories, Inc., Astellas Pharma B.V., AstraZeneca L.P., Auxilium Pharmaceuticals, Inc., Biogen Idec MA Inc., Biom'Up, Bonti, Inc., Braeburn Pharmaceuticals, Inc., Cadence Pharmaceuticals, Inc., Cephalon, Inc., Charleston Laboratories, Inc., Chromocell Corporation, Collegium Pharmaceutical, Inc., Columbia Laboratories, Inc., Coronado Biosciences, Cubist Pharmaceuticals, Inc., Durect Corporation, Frazier Management, LLC, Grace Therapeutics LLC, Grifols, Inc., Heron Therapeutics, Inc., IMMPACT, Imprimis Pharmaceuticals, Inc., Innocoll Pharmaceuticals, Insys Therapeutics, Inc., iX Biopharma Ltd., KemPharm, Inc., KLSMC Stem Cells, Inc., Kowa Research Institute, Inc., Mallinckrodt Inc., a Covidien company, MedRx USA, Inc., Merck Sharp \& Dohme Corp., Mira Pharma, Inc., Myoscience, Inc., Naurex, Inc., an affiliate of Allergan Sales, LLC, Nektar Therapeutics, Novartis Consumer Health, Inc., Novartis Pharmaceuticals Corporation, Pacira Pharmaceuticals, Inc., Pfizer, Inc., PPD Development, LLC, ProFibrix, Inc., Purdue Pharma L.P., QRxPharma, Inc., Recro Pharma, Inc., Regenesis Biomedical Inc., Revogenex, SAI MedPartners LLC, Shionogi Inc., Teva Pharmaceuticals USA, Trevena, Inc., Vertex Pharmaceuticals, Inc., VM Pharma LLC., WEX Pharmaceuticals, Inc. SN reports receiving research grants from Covidien and Endo Pharmaceuticals Inc.; serving on the speakers' bureau for Archimedes, Covidien, Eli Lilly and Company, Johnson \& Johnson, ProStrakan, and Teva Pharmaceuticals; and serving as a consultant for Depomed, Galena, Insys Development Company, Inc., Teva Pharmaceuticals, and Zogenix, Inc.

Ethics approval All procedures in this study were in accordance with the 1964 Helsinki declaration (and its amendments). A valid Institutional Review Board (IRB) reviewed and approved the protocol before study initiation. 
Informed consent Written informed consent was obtained prior to study participation.

Open Access This article is distributed under the terms of the Creative Commons Attribution-NonCommercial 4.0 International License (http://creativecommons.org/licenses/by-nc/4.0/), which permits any noncommercial use, distribution, and reproduction in any medium, provided you give appropriate credit to the original author(s) and the source, provide a link to the Creative Commons license, and indicate if changes were made.

\section{References}

1. Stanley TH. The history and development of the fentanyl series. J Pain Symptom Manag. 1992;7:S3-7.

2. Nelson L, Schwaner R. Transdermal fentanyl: pharmacology and toxicology. J Med Toxicol. 2009;5:230-41.

3. SUBLIMAZE ${ }^{\circledR}$ (fentanyl citrate) injection [package insert]. Lake Forest: Akorn, Inc., 2012.

4. Subsys ${ }^{\circledR}$ (fentanyl sublingual spray), CII [package insert]. Chandler: INSYS Therapeutics, Inc, 2014.
5. DURAGESIC ${ }^{\circledR}$ (Fentanyl Transdermal System) for transdermal administration, CII [package insert]. Titusville: Janssen Pharmaceuticals, Inc, 2017.

6. Parikh N, Goskonda V, Chavan A, Dillaha L. Single-dose pharmacokinetics of fentanyl sublingual spray and oral transmucosal fentanyl citrate in healthy volunteers: a randomized crossover study. Clin Ther. 2013;35:236-43.

7. Rauck R, Oh DA, Parikh N, Koch C, Singla N, Yu J, et al. Pharmacokinetics and safety of fentanyl sublingual spray and fentanyl citrate intravenous: a single ascending dose study in opioid-naïve healthy volunteers. Curr Med Res Opin. 2017;33:1915-20.

8. Rauck RL, Oh DA, Singla N, Koch C, Parikh N, Nalamachu S, et al. Pharmacokinetics and safety of fentanyl sublingual spray and fentanyl citrate intravenous: a multiple ascending dose study in opioid-naïve healthy volunteers. Curr Med Res Opin. 2017;33:1921-33.

9. Smith BP, Vandenhende FR, DeSante KA, Farid NA, Welch PA, Callaghan JT, et al. Confidence interval criteria for assessment of dose proportionality. Pharm Res. 2000;17:1278-83.

10. Parikh N, Goskonda V, Chavan A, Dillaha L. Pharmacokinetics and dose proportionality of fentanyl sublingual spray: a singledose 5-way crossover study. Clin Drug Investig. 2013;33:391-400. 